\title{
Importance of Effective Communication Strategies to Improve Workplace Communication!!!
}

\author{
Shruti Shrivastava, Vineeta Prasad
}

\begin{abstract}
This paper discusses the importance of effective workplace communication for a professional business graduate aspiring to join the industry. Communicating at workplace is a skill, and can be developed by training on specific strategies used in the communication process. Previous studies have highlighted the importance of skill to communicate effectively and its impact on the employability of engineering students. The secondary data review done by the researcher asserted on the need for training the students on skillful communication while they are in their education years. This will support in their work preparedness, and help them in making productive discussions at workplace.

This paper describes the detailed process of a pilot study conducted by the researcher on 102 professional business undergraduates to assess them on their effective communication skills and train them on their preparedness for workplace communication. A pre and posttest method was used to study their responses. The pretest responses highlighted that there were evident gaps in their speaking skills. The researcher devised some communication intervention/strategies that can be used to communicate effectively at workplace with each other. She introduced this intervention to a group of 51 business undergraduate students which were a part of the Experiment group, and trained them on these strategies. A pre and posttest assessment method was used to map the improvement. The results show a significant improvement (more than $45 \%$ ) in the effective communication style of the Experimental group in understanding the communication strategies which added to the work preparedness for these students.
\end{abstract}

This paper is an attempt to discuss the experiment and describe strategies to improve workplace communication between two/more members of an organization thereby enhancing productive business communication.

Keywords: Effective communication, Strategic communication, Productive communication, Soft Skills.

\section{INTRODUCTION}

Effective Communication is a skill that must be effectively practiced at workplace for better work output and results. Several studies identify that effective communication is imperative at the workplace for increasing employee productivity and organizational performance. It is a fundamental need to all administrative functions.

Revised Manuscript Received on November 11, 2019.

* Correspondence Author

Shruti Shrivastava, Research Scholar, AIESR, Amity University, Sector 125, Noida, 201313,Uttar Pradesh.

Dr.Vineeta Prasad, Head of Department, AIESR, Amity University, Sector 125, Noida,201313,Uttar Pradesh.
"Workplace communication is a means of transferring information in such a way that one can make oneself understood to others." Sanchez \& Guo, (2005).

The importance of effective communication in the workplace is undeniable. More so, since the $21^{\text {st }}$ century workplaces are organizations with people belonging to different social, professional and cultural backgrounds-coming together to work for the same goals. Therefore, it is very important for the senior leaders, managers and team members to communicate skillfully so that their work goals and outcomes are reached in lesser time. The format of connecting through teleconferencing and virtual meetings is a growing culture in organizations and hence clear and crisp communication becomes the norm. Bucăţa, George \&Alexandru Marius Rizescu(2017)

Also, we need to realize that today's workplace represents teams with members from up to 4 different generations and age groups. So the difference in attitudes, beliefs and thinking has to match correct communication in order to avoid conflicts. Smith, M. Cecil (2000). It is time that language started being used strategically to facilitate solving several workplace communication situations.

Despite understanding the importance of effective communication within an organization, many organizations face several challenges that emerge due to communication breakdowns and result in creating disconnects and increase in team conflicts. Brun J \& Cooper (2016). These challenges affect performance, compromise success and is a major challenge for administrators across. The challenge keeps on growing more as the professional education system does not train its students on specific workplace communication situations and hence the gap keeps getting wider and also impacts employability of engineers. Mehta, D., and N. K. Mehta (2007). The fresh graduate hired professionals are not able to communicate as required in their job profiles. This has proved to cause a big impact on the utilizing time and bandwidth appropriately and is a direct cost to their organizations.

Effective communication skill in language is an important skill for managers to possess in order to carry out tasks efficiently at the workplace. Striven (1977). The problem continues to grow as one moves up the hierarchy ladder in his organization. A popular study carried out by Odine (2015) in the United States highlighted that only 17 percent of the employees thought that their managers communicated effectively. The managers who took part in the study indicated 
that they spent close to 80 percent of their time on issues related to operational communication. Suggestively, the data shows that while managers may think they are communicating effectively; how the information is actually presented or how it lands across to the listener is based on how employees receive it. Kalla, Hanna K (2005). There are several factors that affects the delivery and receiving of information in order to achieve the intended results, and can be termed as a barrier in communication. With such barriers playing, employees end up creating confused communication between themselves.

\section{Importance of Right Communication in The Workplace}

Although, employees spend most of their time communicating (e.g., sending or receiving information), one cannot assume that meaningful communication occurs in all exchanges. Adu-Oppong, Akua Ahyia \& Emmanuel Agyin-Birikorang(2014). Once a conversation has been made or an e-mail sent, many are inclined to believe that communication has taken place. However, communication has not happened until information and understanding have passed clearly between sender and the intended receiver. To make oneself understood as intended is an important part of workplace communication given every business discussion is outcome based. Therefore, using right questions, phrases and cues are very important to learn and use to achieve better understanding. Ruck, Kevin\&MaryWelch(2012). Studies highlight that below are some of the common workplace situations which need better strategic handling:

Small talk communication

Customer Meetings

Negotiation

Review and Feedback meetings

Making presentations

Handling Webinars

Virtual meetings and teleconferences

E-Mail transaction

Informal discussion/communication

Handling complaints/escalations

We realize all the above communication scenarios are very specific situations that require the people engaged in discussion to reach to a mutually agreeable outcome quickly. Such communication situations require focused communication strategies to be used for results. For example, a simple statement like "You need to improve a lot", given by the Manager during feedback meeting to his subordinate can be very confusing in meaning. Such abstract and vague communication does not give any clear feedback to the employee, and he ends up not taking a focused action for this feedback. If one re looks at the conversation-one realizes that the usage of the word - 'improve a lot' was a phrase which was unclear in transmitting the exact meaning.

Instead, if the Manager would have used a sentence like" Hey, you need to improve in your E-Mail writing skills. I expect you to work on this area this quarter. "would have been a very specific piece of communication.

The workplace communication is filled with several such mistakes which are very common and unrealized, and if one were to quantify the time wasted in interpreting vague messages will be a cost to organizations since my time has a financial implication at workplace. Husain, Zareen(2013).Handling customers effectively using appropriate verbal and written communication is a direct impact on business. Customer interactions is a big area where organizations are continuously demanding attention.

\section{B. Advantages of Effective Communication at Workplace:}

Another thing that has been observed is that many senior leaders and Managers do not realize the importance of communicating effectively at work, and thus do not convey their ideas, organizational goals, vision, etc. very clearly. This results in harping a confused work environment which does not promote open and clear communication, and it can have negative repercussions on the work culture and the employee productivity. Some of the key benefits of effective workplace communication is discussed below Schumann, M., and S. ONeal (2003).

i) Increases job satisfaction- Organizations which encourage an open and easy communication between higher ups and subordinates face lesser employee turnover. When the work environment is friendly- the subordinates are encouraged to speak up their ideas to their Managers regarding work-related issues, and it motivates the employees to work better if their feedback is given due consideration and makes them feel valued in the organization. Thus, effective and open communication in the workplace helps in building loyalty and trust which eventually contributes to greater job satisfaction.

ii)Work productivity Increased- When the workforce of an organization is clear and specific in its communication there will be lesser conflicts. Open communication in the workplace can help clarify information and hugely impacts one's performance at work.

iii)Professional Progress: Workplace conflicts can be resolved through open, clear communication and mutual discussions; this can lead to personal and professional growth.

If one takes a step back and look at the situation, one will realize that the problem needs to be addressed while a student is in his learning phase at school and college. Training students on effective communication strategies while they are in their education will be meaningful. Being prepared for work place specific communication is an emerging requirement from the industry. And putting students through effective training programs where they can learn strategies to communicate in a simulated environment will surely help.

\section{LITERATURE REVIEW}

In order to function efficiently at the workplace, all professional graduates should work upon the most important area that is effective communication skills in English languageJayakar'1, T. Joseph R.\&S. Suman Babu. (2012). When we consider employment- excelling in good communication skills is the way to succeed and that is a fundamental and additional advantage. Globally, an engineering student's success in his recruitment is majorly 
based on his language and behavior competency. Mehta, D. N. K. Mehta (2007). Literature review highlights that the engineering and business graduates passing out of the professional institutes, more so the private institutes are poor in their language skills. The National Association of Software and Services Company (NASSCOM) former president Kiran Karnik remarks that only 25 percent of technical/management graduates are found suitable for employment in the outsourcing industry owing to their lack of abilities to speak or write well in English. P'Rayan, A. L. B. E. R. T. (2008).

In recent passing years, the importance of equipping employers with good oral communication skills in English has grown with the demanding nature of current workplace communication. Stevens (1977) reported that low proficiency in language skill was a difficult factor for employment. He also maintained that many students with low proficiency English language skills are facing difficulties in getting selected by companies. In the workplace contexts, employees need oral communication skills in English language to be successful in their jobs as they must carry out different communicative tasks such as presentations, meetings and negotiations. According to Papa, Michael J., language, especially in oral communication skills would be valuable to solve different problems that take place in workplace situations. In a study made by Kasim and Ali (2010) on the role of effective communication skills in multinational companies the response analysis reported that 71 to 80 percent of the respondents said it was the most important skill required at workplace. They also defined clear areas which require the usage of verbal communication skills in multinational companies viz; giving oral presentations, explaining and demonstrating to subordinates, telephone conversation, informal work related discussions, meetings, and other colleagues.

Studies across highlight that bad communication practices cause a majority of our work problems-from the personal interactions to the professional discussions. It also is a cause of the problems we face at home, or in our personal interactions with others outside of the workplace. Reasons can range from either one passes along the wrong information, or just fails to pass along valuable and correct information. Relationships thrive on communication. It is a fact that for an organization to be successful, it must have all employees capable of sending and receiving information quickly, clearly, accurately and effectively, Boone and Kurtz (2002). We have seen a change in the way we communicate now for it has matured and morphed over a relatively short period-changing from typical face-to-face dialogue to the use of virtual meetings using sophisticated technology designed to increase efficiency and effectiveness. And we now use technology such as text-messaging, email, social media, and video teleconferencing communication, which has made it easier to communicate, but has become much less personal, and consequently misunderstood." We may have traded effectiveness for efficiency" says Conrad (2014).

As Covey (1990) indicates, you don't need to be a management expert to know that, the more effective the communication, the more efficient and productive the people and their activities will be. and Karen Tracy (1988), a high proficiency in English

Mistakes caused by miscommunication creates damage that may cause good customers and key employees to quit. Clutterbuck (2000) states that, the smooth functioning of a workplace is dependent on the cooperation between coworkers and, in order to cooperate well, coworkers need to be able to communicate effectively.

\section{A. Lack of Effective Training:}

Unfortunately, according to Blair, D., and S. Jeanson. (1995). despite the professional training given to undergraduate students, there is still a skill gap in workplace situations. It is mentioned that there are significant gaps between the expectations of industries and training universities offer to the students.

Training needs to be imparted in excelling all four language skills in communication. Studies highlight that an employee spends almost $75 \%$ time at workplace in just making communication using different skills viz Reading, Writing, Speaking, Talking and Listening. Out of these the biggest gap is observed in skill of effective talking (making interactions) and listening actively. Ober, S. (2001)

The researcher has identified several factors that contribute to ineffective communication at workplace. These factors are very subtle and remain unnoticed unless one gets trained on them. The researcher devised strategies to be given as a focused intervention program to professional students. She tested the effectiveness of these strategies on a group of 51 students and was successful in increasing their level of language communication -making it more effective.

Odine (2015) reviewed communication problems in managing organizations, found out that only the identification of these issues in the workplace did not prevent their occurrence. It is significant to get trained on the strategies that will ensure communication problems that affect employee and organizational productivity adversely. Hedman and Valo (2015) believed that the discussed problems occurred because of the inability to speak up during meetings and Odine (2015) emphasizes on the use of improper channel and the presence of unclear information as the key shortcomings in the communicative process within organizations. Moreover, the author concluded that many professionals did not pay attention to the characteristics of the audience/recipient of their message (for instance, their background and knowledge).

Odine (2015) recommended focusing on the receiver when designing messages and engaging in the communication process. The information provided by managers should be specific and comprehensible so to minimize confusion. The channel used for communication should be smooth because different people need to access it. The information should be passed through the most effective media channels and should convey a message that can be understood by any stakeholder within the organization.

\section{B. Factors Impacting Effective Communication at Workplace:}

There are several factors that impact the effective speaking practiced by the workforce at their workplace. These factors hinder the process of communication and understanding. 
Wilson, John P (2005). These are very common and much talked about factors and proper training on these factors will help the professional students to take on communication with the right focus at their workplace. Below is a list of factors coupled with strategies to overcome them with some exercises that can help in getting the desired results. For each contributing factor, the researcher developed strategies to overcome the negative factors that impacts the workplace communication. The researcher developed these strategies which included reviewing academic literature/journals and studying commercial training material relevant to workplace Communication. The exercises were developed to test the effectiveness of each strategy. The exercises were then offered to a group of final year management students as part of the Survey.

Factor 1: Use of Abstract Words/Phrases: One of the factors majorly contributing towards lack of effective communication is the use of abstract words. Abstractness in expression creates confusion and ambiguity in conversation.

Role Play example of using Abstract language:

A: Hi, let us discuss your performance.

B: Yes, okay, you are right...please go on

A: I feel you have given an average performance this year. I see a lot of scope for improvement in you. I will appreciate if you start focusing more on your work.

B: I will try(sighs!!)

Strategy to overcome: To use concrete words and sentences in writing and speaking bringing more clarity.

Material Required: Cue card, Pen, Paper

\section{Exercise: Abstract VS Concrete}

Student are given two sets of cue cards with abstract words on one and crisp words on the other.

Cue Card Abstract: I will call u soon, will get back to you, your performance was poor, you need to improve, you need to work more.

Instruction: Student A speaks on a given topic using the abstract words. Student B writes notes down his confusion and asks questions after Student A stops speaking. The facilitator discusses the confusion created by using abstract words.

Cue Card Concrete: I will call you by EOD, I will get back to you by tomorrow first half, your performance in the area of managing database was poor, you need to improve on meeting your deadlines.

Instruction: Student B speaks on a given topic using the concrete words. Student A writes notes down his confusion and asks questions after Student A stops speaking. The facilitator discusses both the cue cards and helps students understand the difference between using abstract and concrete words.

The exercise highlights importance of using concrete words in your communication at workplace. The confusion in understanding message clearly decreases when one uses concrete words and saves time in making your message clear and understood

Role play using Specific communication

A: Hi, how have been? I wanted to discuss your last quarter performance with you.
B: Sure, I am looking forward to discuss my performance also.

A: At the outset, I will like to congratulate you for achieving your targets last quarter. Well done!! I have lot of hopes from you. I suggest you focus on developing your writing skills in the coming quarter.

B: Thankyou Sir, I will start working as guided by you.

Factor 2: Lack of Using Specific Words: This factor is also an important impediment in speaking effectively and leads to confused speech.

Role Play using vague words:

A: I want you to complete the work for me.

B: Which work?

A: The same work which we discussed yesterday and once you finish it give me a call same time.

B: We discussed on 3 things yesterday which work are you referring to?

Strategy to overcome: To understand the difference between crisp and ambiguous words/communication.

Exercise: I Know You Believe You Understand

Instruction: The quote below is presented to participants, and they are asked to explain what they believe its meaning is.

"I know that you believe you understand what you think I said, but I am not sure you realize that what you heard is not what I meant!"

The Student A presents the Handout 4-A to participants and ask them what they think the statement means.

All participants to have differing interpretations, if any, of this very confusing statement.

Student A then simplifies the quote using exact words and clarifies the meaning to the participants.

You think you understand my message. However, I have my doubts. Can you please repeat what you understood?

To highlight how unclear communications can lead to confusing interpretations and to emphasize the need for clarity when communicating

Role play using Crisp Communication:

A: Hey, I suggest you complete your outlier data sheet by EOD today. It is a high importance task.

B: All right, I have completed it half and shall send you the complete data by $3 \mathrm{pm}$ today. Hope that is fine with you?

A: Yes, that will be good

Factor 3: Lack of using appropriate tone while delivering the message.

Strategy to overcome: To know different tones and its effect on listener (Aggressive, Assertive and Persuasive tone)

Exercise: Tones

Instruction: Role Play between students using Aggressive, Assertive and Persuasive tone in speaking.

Student A.B and C take roles as aggressive, assertive and persuasive speaker in a Role Play with students D, E and F.

They exhibit their behavior using their nonverbal cues, face expressions and tone during the interaction.

Factor 4: Lack of using one's own vocabulary bank for use in speaking: This factor is a common problem with most speakers. They don't use all the words from their own vocabulary bank in communication. For example, if a speaker has 500 words in 
his personal vocabulary bank. Out of those if he keeps using almost 30 to 50 words only during his daily communication, he will always feel he/she has poor vocabulary.

Strategy to overcome: To be aware of how many words one knows. Maintain a small word journal and note all words you know.

\section{Exercise: Use your Bank}

Instruction: The faculty asks all students to think of 10 words which they know but don't use in their written/verbal communication.

Then the faculty instructs students to present on a topic using all the words they wrote on the card.

This exercise will help the users to become aware of the several words which are already a part of their vocabulary.

It will also help in improving their vocabulary once they start using these words in their communication

Factor 5: Weak pronunciation is also a big factor impacting fluency in speaking. The impact of local accents, regional style of speaking and being tongue tied can be several factors contributing to poor pronunciation.

Strategy to overcome: Take feedback on your pronunciation from one's friends and colleagues.

Becoming aware of correct pronunciation

Exercise: Pronounce right the first time

Instruction: 1) Student A reads a paragraph loudly. Student B listens him and notes his pronunciation. Once Student A has read, Student B speaks the words that were incorrectly pronounced by Student A.

Then they switch their turns and proceed the same steps.

2) After the exercise the faculty clarifies the correct pronunciation by using pronunciation tools and makes students practice on them etc.

This exercise helps in getting conscious of one's own level of correct and incorrect pronunciation and improve.

Factor 6 Inability to Clarify information: Leadership is a skill which needs to be practiced every day. At workplace during discussion meetings and calls, it is important to understand the complete information being discussed. Probing is an available tool which enables us in receiving appropriate information from the speaker. The technique of asking right questions (open ended) helps the listener in understanding the message to its appropriateness.

Exercise: 'Ask to clarify'/'Probing'

Cue Cards: How, can you, please help me understand, why so, how so, Can you detail out, Request you to elaborate Instruction: Student A reads a paragraph loudly. Student B listens him and notes his points. Once Student A has finished, Student B phrases open ended questions using words from the cue card to clarify points not understood. Then they switch their turns and proceed the same steps. This exercise helps in giving practice of asking open ended questions and achieve better clarity on the information.

\section{Role Play using Probing:}

A: I think you have a tendency to argue on everything I tell you. I don't think we can work together on this further.

B: (Reacting) (Destiny of conversation is negative)

And you think you never argue with me?

Probing: Destiny of relationship is positive

A: Okay, I hear you. For my understanding can you please share an incident where you felt I was arguing?
Factor7 Inability to Paraphrase: Paraphrasing is a very important strategy used in business discussions. It is the ability of crisply putting across the information you have received from the speaker during interaction. The inability to paraphrase message and confirm with speaker is one of a major problem at workplace. Paraphrasing technique will enable the listener to understand the key issues better and the speaker also understands that his message has been taken in fully or not. As the listener paraphrases, the speaker can always fill up the missing information and achieve better clarity in communication with each other.

Strategy to overcome: Paraphrase the gist of the message as heard and confirm with the speaker.

Exercise: This is what I understood

Cue Card: Is this what you are saying, So, what you are saying is, If I understand correctly

Instruction: Student A reads a paragraph loudly. Student B listens him and notes key points. Once Student A has read, Student B paraphrases the message understood by using phrases on the cue card and confirms with the speaker.

Student A listens and then fills up the missing information or confirms that his message has been understood correctly. Then they switch their turns and proceed the same steps. This exercise helps in learning paraphrasing technique and improve clarity in perception and the information being exchanged. This technique helps a lot while handling conflict situations or long discussion meetings

\section{Role play highlighting difference in reacting and using paraphrasing as a tool:}

A: I think you have been slow at your tasks past couple of days. I got this feedback from Mark as well on the errors in reports you made, and I am really disappointed

B (Reacting): Slow??What are you saying? How can you judge me like that?

$\mathrm{B}$ (Paraphrasing)

Okay, I hear you....so what you are saying is that since Mark complained about me: on the errors in reports, you think I am slow in my role?

A: Not slow in the role. I meant careless with reports. Mark is our customer; we cannot have him unhappy.

B: I understand you John and agree with you. There was some outlier data which was interfering and hence the error. I have corrected the same. I will talk to Mark myself and clarify.

John: Sure. that will be helpful

Factor 8 Lack of confidence: The low confidence in speaking fluently is a key factor that affects speaking fluently. This is majorly because of less practice in speaking on different issues.

Strategy to overcome: Confidence can be built by regular practice of speaking on different topics extempore.

Exercise: Extempore

Instruction: The faculty supplies chits to Student A with different topics written on it. Then the student is asked to stand before a Mirror and start speaking on the topics. Student A starts speaking on the first topic. He speaks as much as he can and then stops and starts speaking on the next topic on the list as much as he can. 
This exercise when continued regularly will slowly improve confidence in speaking fluently.

\section{RESEARCH HYPOTHEIS:}

The study wants to discuss the impact of using effective communication strategies as developed by the researcher on a sample group and discuss results. The null hypothesis for this study is as below which the researcher wants to nullify:

$H_{0}$ : There is no statistical difference in the mean scores of the two groups, and in the level of effective communication in students after training them on specific communication strategies.

\section{RESEARCH METHODOLOGY:}

The present research was carried out in a couple of steps which are described below. The researcher designed a Questionnaire with 10 items as a pre-test revolving around factors impacting in communicating effectively. The pretest was validated for its Reliability by running a Cronbach's alpha test. The Cronbach value was 0.846 which was an acceptable value and represented the test having high reliability.

1) Pre-test: The author conducted a pre-test survey with a group of 102 students. These students belonged to 5 Management Institutes around Delhi NCR region. The survey questions were designed professionally to assess the communication problems. We focused on designing questions around communication etiquette given our overall goal was to help students improve their soft skills when they are employed, and referred some online resource also. (Appendix 1) We expected students, in general, to have lower scores on this test.

2) The Questionnaire was built on a Likert scale ranging from responses Strongly agree to Strongly disagree. The Reliability of the Questionnaire was calculated using Cronbach alpha value. The Cronbach Value was 0.846 which is highlights that the items on the questionnaire had strong internal consistency.

\begin{tabular}{|c|c|}
\hline Question & 10 \\
\hline $\begin{array}{c}\text { Sum of total } \\
\text { variance }\end{array}$ & 15.58 \\
\hline total variance & 65.1875 \\
\hline Cronbach Value & 0.846 \\
\hline
\end{tabular}

Table 1: Cronbach Alpha

2) Intervention: Intervention: In the next step, the student group was divided into two groups of 51 students each. These groups were named the Control $\operatorname{Group}(\mathrm{A})$ and the Experimental Group(B). The researcher then administered the experimental group with the strategies developed and trained the students on the same for a period of 10 days. The Experimental group was trained on the different communicating strategies as developed by the researcher.
The exercises were demonstrated to students and given practice upon using a blend of concept classes, webinars and Role play activities using exercises on effective communication created by the researcher.

3) Post-test (knowledge retention): Post the intervention was administered, a posttest was given to Group A and B to measure the improvement in their scores. The Experimental group that was coached to communicate better, scored higher and exhibited an improvement of $50 \%$ over the Control group.

\section{DATA ANALYSIS AND FINDINGS:}

A. Pre-test: The answer to each question for each respondent was converted to a point system. (Refer Table 5 in appendices). The sum total scores for all questions were calculated for total 102 students.

\section{B. Post-test:}

This survey was done on the two groups (control and experimental groups) again after the intervention. The Aggregate Listening Score was calculated for each respondent in the two groups. As stated earlier, our goal was to see if the intervention helped the experimental group improve their effective communication. In order to compare the response for pre and posttest for the group B-Experimental group, we performed a single factor Anova test using Excel.

The findings show that the response from the same group before and after the intervention is quite different. In fact, was an increase in the Aggregate Scores on effective communication after the intervention. The one-way analysis of variance (ANOVA) was used to determine whether there are any statistically significant differences between the means of two independent (unrelated) groups.

The results indicate that the $\mathrm{P}$ value is very small, and that means that the two groups (pre and post experimental group) had significantly different Aggregate scores. The post-test communication scores improved for the group B-Experimental group.

The Anova single factor clearly indicates that there is a significant change in the Experimental Group A scores (Mean scores) of both pre and posttest. As one can see the $p$ value is less than .01 i.e 9.72E-14 for the Experimental group. Hence the null hypothesis is rejected and the results represent a high statistical difference in communication scores of two groups.

Anova: Single Factor
SUMMARY
\begin{tabular}{|l|r|r|r|r|}
\hline \multicolumn{1}{|c|}{ Groups } & Count & \multicolumn{1}{c|}{ Sm } & Average & Variance \\
\hline control & 51 & 65 & -1.27451 & 7.363137 \\
\hline experimental & 51 & 362 & 7.098039 & 40.6102 \\
\hline
\end{tabular}

ANOVA

\begin{tabular}{|l|c|c|c|c|c|c|}
\hline Source of Variation & \multicolumn{1}{|c|}{$\boldsymbol{\text { df }}$} & $\boldsymbol{M S}$ & $\boldsymbol{F}$ & P-value & Fcrit \\
\hline Between Groups & 1787.539 & 1 & 1787.539 & 74.5222 & $9.71767 \mathrm{E}-14$ & 3.936143 \\
\hline Within Groups & 2398.667 & 100 & 23.98667 & & & \\
\hline Total & $\mathbf{4 1 8 6 . 2 0 6}$ & 101 & & & & \\
\hline
\end{tabular}

Table 2: Anova Single Factor Analysis 


\section{DISCUSSIONS}

The researcher studied the several factors impacting effective communication at workplace and developed strategies which can be introduced as a part of training exercises for the undergraduate business/management students while they are in their studies. In order to showcase results, the researcher conducted a pilot test and the results of the test show significant improvement in style of communication of the experimental group.

The results highlight an important point on requirement of right training for achieving a productive communication style. And improvement can surely happen; given the stakeholders involved understand the benefits of timely training. With each passing year the job market is getting more stringent on the quality of the recruitments and one's communication style is a big factor.

Therefore, the researcher wants to recommend using these strategies in activity labs or language tutorials at professional institutes on Delhi NCR. The focused training will impact the work preparedness of the new engineers who join the workforce every year.

\section{CONCLUSION}

From the above findings and discussions, we may conclude the importance of workplace communication and benefits of using communication effectively to get our work done. The researcher has based this study to Delhi region and observed positive results in the sample group's performance. This is a highly valuable finding and is recommended to be implemented in Business Schools.

\section{REFERENCES}

[1] Guo, L. Christina, and Yesenia Sanchez. "Workplace communication." Organizational behavior in health care (2005): 77-110.

[2] Bucăţa, George, and Alexandru Marius Rizescu. "The role of communication in enhancing work effectiveness of an organization." Land Forces Academy Review 22.1 (2017): 49-57.

[3] Smith, M. Cecil, et al. "RRQ Snippet: What Will Be the Demands of Literacy in the Workplace in the Next Millennium?." Reading Research Quarterly 35.3 (2000): 378-383.

[4] Brun, J., and Cary Cooper. Missing pieces: 7 ways to improve employee well-being and organizational effectiveness. Springer, 2016.

[5] Strevens, Peter. "New orientations in the teaching of English." (1977).

[6] Odine, Maurice, and A. Dean. "Communication Problems in Management." Journal of Emerging Issues in Economics, Finance and Banking 4.2 (2015): 1615-1630.

[7] Kalla, Hanna K. "Integrated internal communications: a multidisciplinary perspective." Corporate Communications: An International Journal 10.4 (2005): 302-314.

[8] Adu-Oppong, Akua Ahyia, and Emmanuel Agyin-Birikorang. "Communication in the workplace: Guidelines for improving effectiveness." Global Journal of Commerce \& Management Perspective (2014): 208-213.

[9] Ruck, Kevin, and Mary Welch. "Valuing internal communication; management and employee perspectives." Public Relations Review 38.2 (2012): 294-302.

[10].Husain, Zareen. "Effective communication brings successful organizational change." The Business \& Management Review 3.2 (2013): 43

[11] Schumann, M., and S. ONeal. "Communication strategies that can help you soothe today's anxious workers." Pay for Performance Report 3.7 (2003): 1-4.

[12] Jayakar ${ }^{1}$, T. Joseph R., and S. Suman Babu. "Professional communication for better work-life balance." (2012).

[13] Mehta, D., and N. K. Mehta. "Communication skills for engineering professionals." Adit Journal 4.1 (2007): 89-95
[14] P'Rayan, A. L. B. E. R. T. "Engineering English: A critical evaluation." Unpublished Ph. D. thesis), Annamalai University India (2008).

[15] Papa, Michael J., and Karen Tracy. "Communicative indices of employee performance with new technology." Communication Research 15.5 (1988): 524-544

[16] Kassim, Hafizoah, and Fatimah Ali. "English communicative events and skills needed at the workplace: Feedback from the industry." English for Specific Purposes 29.3 (2010): 168-182.

[17] Boone, Louis Eugene, and David Lee Kurtz. Contemporary marketing. Dryden Press, 1992.

[18] Conrad, David. "Workplace communication problems: Inquiries by employees and applicable solutions." Journal of business studies quarterly 5.4 (2014): 105.

[19] Covey, S. R. "The seven habits of highly effective people. New York: Fireside. Covey, SR (1991). Principle centered leadership." (1990).

[20] Clutterbuck, D., and D. Lazidou. "Communication competence and business success: A comparative review of communication programs." IABC, Chicago (2001).

[21] Blair, D., and S. Jeanson. "Workplace oral communication curriculum." (1995).

[22] Ober, S" Contemporary business communication". Boston, MA: Houghton Mifflin(2001)

[23] Hedman, Eerika, and Maarit Valo. "Communication challenges facing management teams." Leadership \& Organization Development Journal 36.8 (2015): 1012-1024.

[24] Wilson, John P., ed. Human resource development: learning \& training for individuals \& organizations. Kogan Page Publishers, 2005. 
Importance of Effective Communication Strategies to Improve Workplace Communication!!!

\section{APPENDICES 1}

Pre and Posttest: Effective Communication

\begin{tabular}{|c|c|c|c|c|c|c|}
\hline No & Question & Not at all & Rarely & Sometimes & Often & Very Often \\
\hline & $\begin{array}{l}\text { I'm surprised to find that people dont } \\
\text { understood what I've said.n my } \\
\text { communication and I need to clarify again } \\
\text { and again. }\end{array}$ & & & & & \\
\hline & $2 \mid \begin{array}{l}\text { I have a favourite list of ten words or so } \\
\text { which I often use in my verbal and written } \\
\text { communication }\end{array}$ & & & & & \\
\hline & $\begin{array}{l}\text { I think using authority and instructional } \\
\text { tone with my juniors is the best way to get } \\
3 \text { work done faster. }\end{array}$ & & & & & \\
\hline & $4 \begin{array}{l}\text { I like to speak in long sentences -using } \\
\text { complex words in order to impress the other } \\
\text { person. }\end{array}$ & & & & & \\
\hline & $\begin{array}{l}\text { I don't feel the importance to notice the body } \\
\text { language of the other person when I } \\
\text { communicate with him. }\end{array}$ & & & & & \\
\hline & $\begin{array}{l}\text { If I don't understand something, I tend to } \\
\text { keep this to myself and figure it out later } \\
6 \text { rather than asking questions on it. }\end{array}$ & & & & & \\
\hline & $\begin{array}{l}\text { I speak in an aggressive manner with others } \\
\text { as that is the best way to get work done from } \\
\text { them. }\end{array}$ & & & & & \\
\hline & $\begin{array}{l}\text { I use jargons in my speaking a lot as this } \\
\text { makes me speak fast and complete my } \\
\text { communication with all. }\end{array}$ & & & & & \\
\hline & $\begin{array}{l}\text { Before I want to communicate, I think about } \\
\text { what the person needs to know, and how } \\
\text { best to convey it. }\end{array}$ & & & & & \\
\hline & $\begin{array}{l}\text { I try to help people understand the } \\
\text { underlying concepts behind the point I am } \\
\text { discussing. This reduces misconceptions } \\
\text { and increases understanding. }\end{array}$ & & & & & \\
\hline
\end{tabular}

